\title{
Regenerative Urban Space: A Box for Public Space Use
}

\author{
Elisabetta Ginelli, Gianluca Pozzi, Giuditta Lazzati, Davide Pirillo \\ and Giulia Vignati
}

\begin{abstract}
The essay addresses the issues of centrality and reactivation of urban public spaces, illustrating the project 'multiplyCITY: container TOOLS.' The project is composed of a system of 'devices' that can be placed in urban or natural contexts and is capable of hosting multiple functions for citizens, even in total energy autonomy. The project was presented and mentioned in the competition 'Volumezero design competition: Unbox 2017: ReThinking Containers,' completed in 2018. It consists of a system of sheltered spaces, modular, and flexible for temporary use. The system is defined by the adoption of principles assumed as design criteria: sustainability, multifunctionality, flexibility, temporariness, and customizable use. Through the combination of guiding principles, the reuse of dismissed shipping containers and the industrialized installation method, it has been possible to propose a TOOL that could be used in policies and actions aimed at urban regeneration. The design proposal has a multifunctional nature and is able to enhance the open space, assuring fast execution times and costs containment during construction, management, and maintenance. This is achievable through the use of dismissed shipping containers, which are reusable and convertible over time through minimal and low-cost interventions, offering more lives to a highly durable object.
\end{abstract}

Keywords Multifunctional tools $\cdot$ Shipping container $\cdot$ Urban regeneration • OFFGRID $\cdot$ Re-appropriation of public space $\cdot$ Circular economy

\section{Cultural Background}

The quality of urban spaces is expressed and marked by the environmental/ecological, human/social, structural, and symbolic functions that such spaces may adopt (Stiles 2009).

E. Ginelli (凶) · G. Pozzi · G. Lazzati · D. Pirillo · G. Vignati

Architecture, Built Environment and Construction Engineering-ABC Department, Politecnico di Milano, Milan, Italy

e-mail: elisabetta.ginelli@polimi.it

(C) The Author(s) 2020

S. Della Torre et al. (eds.), Regeneration of the Built Environment

from a Circular Economy Perspective, Research for Development,

https://doi.org/10.1007/978-3-030-33256-3_14 
Compared to the planning processes of large city areas fostered by huge investments, the regeneration and the reclamation of abandoned and degraded urban spaces are often hampered by administrations due to the lack of assets. Design solutions based on the recovery, reuse, and recycling of buildings, materials, and components, within the circular economy scenario, for temporary or permanent projects are winning proposals, from both the environmental and the financial point of view (Ginelli et al. 2019).

Furthermore, urban regeneration represents a practice for the development of strategies which can overcome some critical aspects of contemporary cities: 'Innovative experiences carried out within the international context link urban regeneration to the wider governance scenario, pointing out operational behavior and research approaches that do not merely make urban regeneration as a design matter exclusive, but push it out as strategic opportunity for creating a new physical order and new, upgraded, urban performances' (Losasso 2015).

Indeed, urban regeneration is a combined set of urban/building projects and social initiatives that include the redevelopment of the built environment and the reorganization of urban assets. The main goal is the search for urban, environmental, social, and economic quality. Its outcome should be an integrated process for a continuous improvement over time. The keywords are polycentric re-balance, densification, hybridization, participation and inclusion, eco-efficiency of resources treatment, investment efficiency, economic and social enhancement.

Urban public spaces, as open unbuilt areas between buildings, play a strategic role with respect to the future of cities, assuring comfort and environmental preservation.

Nowadays, the theme of public space is extremely relevant since cities, marked by social inequalities and various limits, requires the presence of public spaces as key factors of urban relationship and participatory elements of citizen life. These spaces represent essential goods for comfort and life quality.

We are aware that urban space is considered as place (Augé 2009) if it is recognized as a distinctive space, an area full of sociality, participation, and symbolization, a testament of the strong link between social aspects and collective history (Dardi 1992).

The place is the balanced combination of space and identity, because it can make history and leave a 'memory' even in temporariness.

We assumed the concept of space, place, aggregation, shared space, network system, time, and strategy as a methodological key for the project. The combinations space/place, sharing/relationship, artificiality/nature, temporary/permanent, connectivity/integration, open/close represent essential reference criteria to design a place where the user belongs to his community.

We therefore propose the use of active and stimulating devices that meet functionality and safety requirements and are capable of triggering interaction between the cultural, social, landscape, environmental, economic, and institutional dimensions of a context: They are an active connection hub. The challenge is to design multi-dimensional and multifunctional spaces. 
Indeed, the dynamism of change is representative of place quality. This statement fully explains our project proposal. Multifunctionality is hereby assumed as a mandatory characteristic for the redevelopment of public space. It is used with twofold meanings: multifunctional use of space as the interrelation between functional, social, and morphological possibilities, in which activities can be integrated and coexist simultaneously; multifunctionality over time of the object as its potential and useful transformation, guaranteeing new lives to it.

The activation of regeneration projects through a strategic approach based on a gradual reactivation, on the promotion and active involvement of multiple actors, increases the attractiveness and quality of the urban environment in order to satisfy needs and reach the greatest number of users. The result of these actions enables to 'achieve something greater than the sum of the parts,' determining an increase in the value of the space for the benefit of the community (Stiles 2009). The gradual reactivation allows for an economically feasible action, monitoring the results over time, and an urban regeneration process, replicable in different contexts thanks to its adaptability.

\section{The Contemporary City as MultiplyCITY: The Framework}

The contemporary city can become an experimental center of progress and creativity, also thanks to the adoption of new drivers for sustainable growth, innovation, creation and dissemination of knowledge and information: These processes tend to benefit greatly from the physical proximity and diversity offered by cities, especially the large ones (Santagata 2009).

Within the recognizable image of the city network of spaces, hierarchies, and connectivity (Lynch 1960), the public space plays a strategic role to foster city vitality, individual fruition and social condensation, becoming a magnetic space admitting aggregation, hosting activities and offering opportunities (Carta spazio pubblico 2009).

Urban open spaces of citizenship nuclei are cornerstones on which to found improvement. They are the starting points to propose a space assuming a sharing and cohesion significance, thus producing a supplementary value based on the relations it establishes between the primary functions (by design) and the complementary functions (already present on the territory) (Ginelli 2015).

The call 'UnBox 2017: ReThinking Containers' announced by Volzero ${ }^{1}$ addresses the themes of reuse and recycling through the Realization of architectural works that contribute to the urban regeneration of city public spaces, in a scenario of multiple initiatives concerning the reference framework synthetically illustrated below and particularly the circular economy.

\footnotetext{
${ }^{1}$ Volzero: a digital platform that deals, through works, with the themes of architecture, design and landscape, promoting competitions aimed at young designers and students (www.volzero.com).
} 


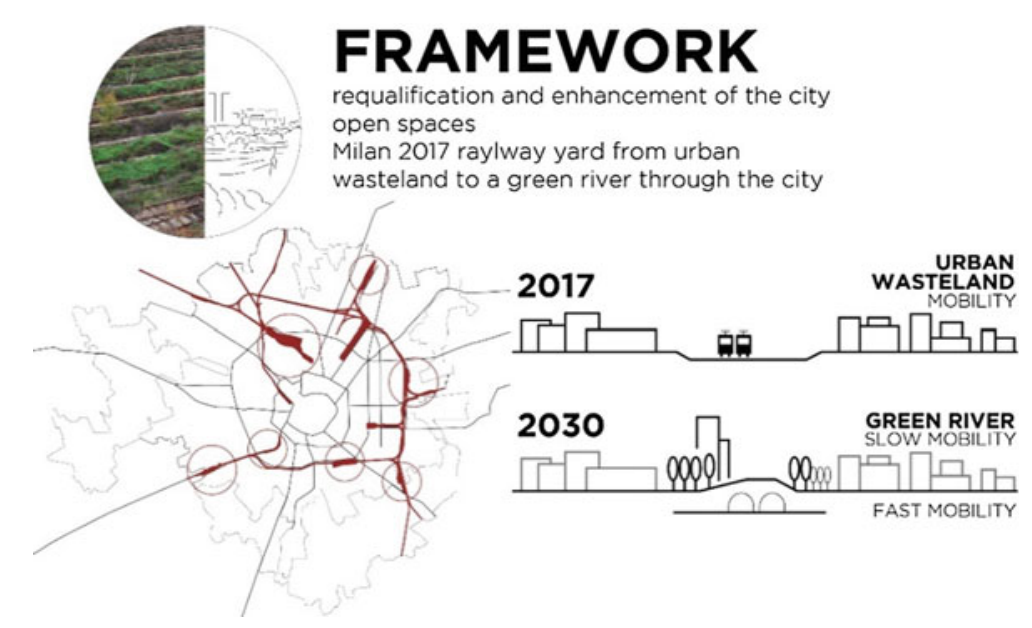

Fig. 1 Project framework: the transformation of Milan's dismissed railway yards

The call focuses on the inventive functionality of shipping containers for the large public by using them to craft space in the public environment, in order to highlight the future of the public space experiencing their new functions thanks to cutting and manufacturing carpentry interventions.

Participants from 57 countries, for a total of 323 proposals, have explored different ways of designing spaces that involve communities with solutions repositionable in every part of the world (Fig. 1).

The contextualization of the project proposal within a specific site, identified in relation to its cultural environment, was one of the evaluation criteria. In a metadesign scale, the presented proposal has been included in the initiative 'Dagli scali, la nuova Città.' The initiative promotes a strategic vision of Milan in favor of a change in the mobility and image of the city, through the requalification and enhancement of seven dismissed Milan railway yards. ${ }^{2}$

\section{Theme and Context}

The reconversion of the railway yards is an opportunity to reconnect the suburban areas with the center of Milan. Figure 2 shows the multiplyCITY: container TOOLS placed into Porta Romana railway yard, as compared to the aforementioned seven areas: from an empty urban space to a new attraction center for sports and market.

Within the substantial urban requalification intervention of the dismissed areas, which will be redeveloped into new neighborhoods featuring large greenspots, the

\footnotetext{
${ }^{2}$ Iniziative organized by Comune di Milano, Regione Lombardia, and Ferrovie dello Stato (http:// www.scalimilano.vision/).
} 


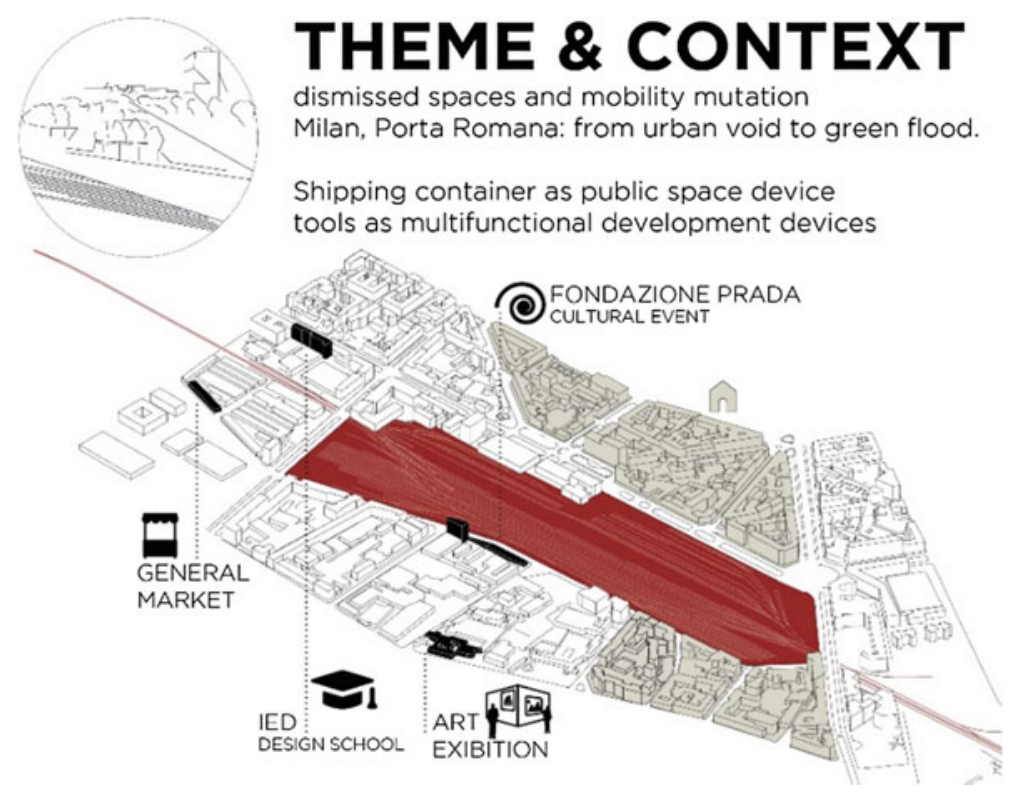

Fig. 2 Context of the project proposal: dismissed space in Porta Romana, Milan

incremental development proposal will start with a first phase aimed at enabling the use of new parks and open spaces offering enough environmental comfort when plants are not completely grown.

The solution triggers a dialogue between the surrounding areas and the designed multifunctional devices for 'public utility,' proposing a replicable model which is flexible to demographic changes and the dynamism of the site.

The developed project proposal supports urban transformation processes within open public spaces. In a logic of incremental development, the project is articulated in three temporal phases corresponding to the most significant moments of the transformation of the context:

- the first phase, following area reconversion operations, corresponds to the reappropriation of a portion of the open space by citizens; through the project's spatial devices, a limited number of activities_-including temporary ones-will be included within the area;

- the next one, a transitory phase toward the proposal's conclusion and the total reopening of the area, entails the introduction of a range of activities through different modular configurations of spatial devices. The identification of the activities with a greater guarantee of success results from the responses recorded during the first phase, which determine the diversification by functionality, user target, and temporality of use of the spaces; 


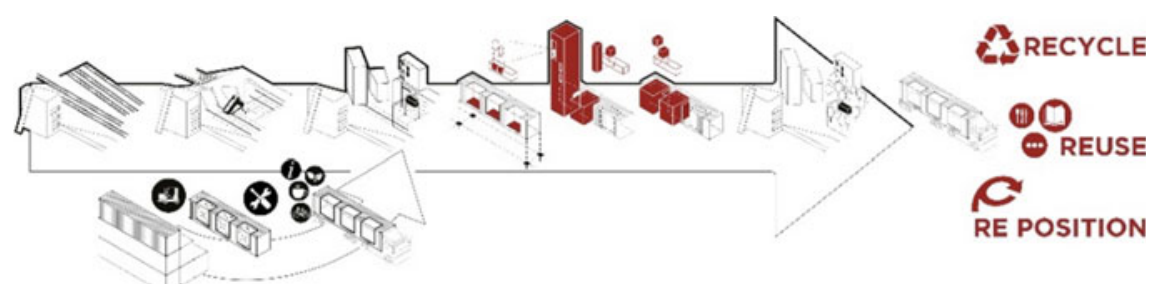

Fig. 3 'multiplyCITY: container TOOLS' main temporal phases according to incremental development

- the third phase corresponds to the total reopening of the area, in which part of the devices has been replaced by permanent structures provided by the area intervention master plan (Fig. 3).

The device can be repositioned and reused to ensure the circularity of the intervention and therefore a second life in another context, due to its possibility of being easily reusable or, in different scenarios, of being recycled or to permit the reusability of its components.

\section{Multifunctional Container TOOLS}

The application of a circular model for regeneration processes sees the 'Shipping Containers Building' as an urban space resource within a scenario of assets reduction through the reuse of dismissed boxes (saving additional energies and assets for the realization of new spatial objects/modules).

Shipping containers' main purpose is the transportation of goods; this characterizes their realization according to dimensional and material standards, which assure ease of transport, structural strength and global distribution (Kotnik 2008; Kramer 2015). These features, together with modularity, allow for several different conformations that lead to the adoption of design strategies being based on their reuse, through creativity and functionality; a potentiality and an economically viable solution for abandoned spaces, even in a condition of scarce resources.

The project consists of the placement of a spatial device composed, in its basic configuration, by a dismissed 40' HC shipping container (length 12,192 m, width $2,438 \mathrm{~m}$, height $2,896 \mathrm{~m}$ ). Through carpentry operations on the external cladding sheet, cuts, and openings, it is possible to increase the useful surface and arrange the metal structure. Such interventions allow to introduce further elements, for example canopies obtained from reusing the removed sheet metal, equipment elements for street furniture or the possibility to connect additional shipping containers to increase the usable space. These elements, clamped together in workshops, are called TOOLS and enable the device to react to multiple activities in a multifunctionality logic (Fig. 4). 

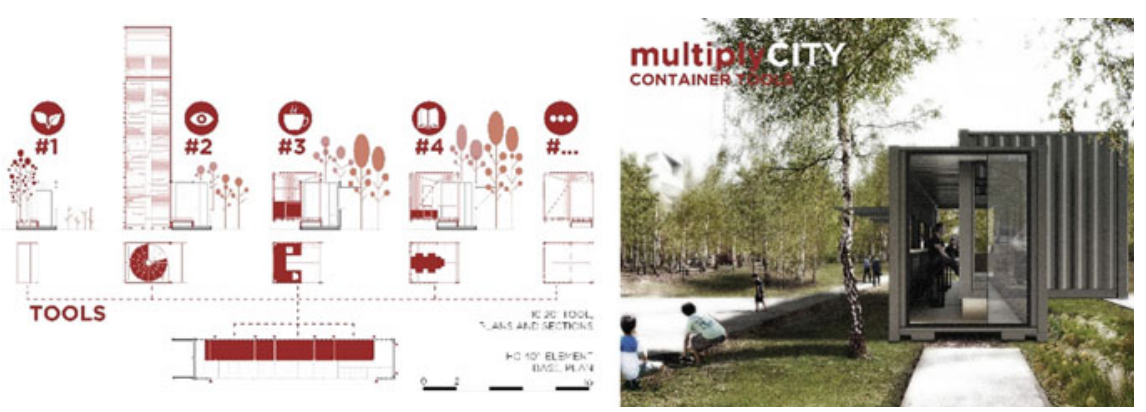

Fig. 4 'multiplyCITY: container TOOLS' multifunctional TOOLS

The TOOLS define a set of reversible solutions. The 40' HC shipping container in its basic configuration includes cutting and opening operations conditioned by two main reasons: not compromising the integrity of the steel structure and allowing the interface between the basic configuration and three models of shipping containers (10' BOX, 20' and 40' HC). The cuts and the openings have the same size as the three types of shipping containers which can be combined to define the multifunctional TOOLS, since structural components and dimensions have been standardized except for the length.

These multifunctional TOOLS enable configuration changes in order to increase the useful life of the spatial device and offer a response to the development of the context, in relation to the needs of the area and the resources available (Fig. 5).

The basic 40' HC shipping container permits different configurations by adding a first element, TOOL $\propto$, which is an equipped platform. This object is a support for street furniture, similar to a seat allowing the insertion of vases for growing plants, and consists of a technical compartment for lighting the area as well as some charging

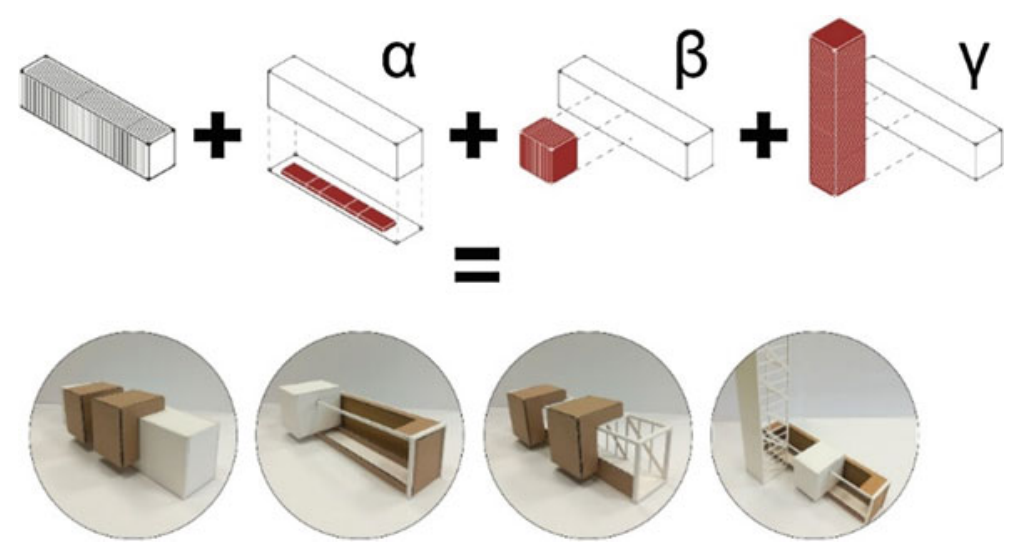

Fig. 5 'multiplyCITY: container TOOLS' multifunctional TOOLS 


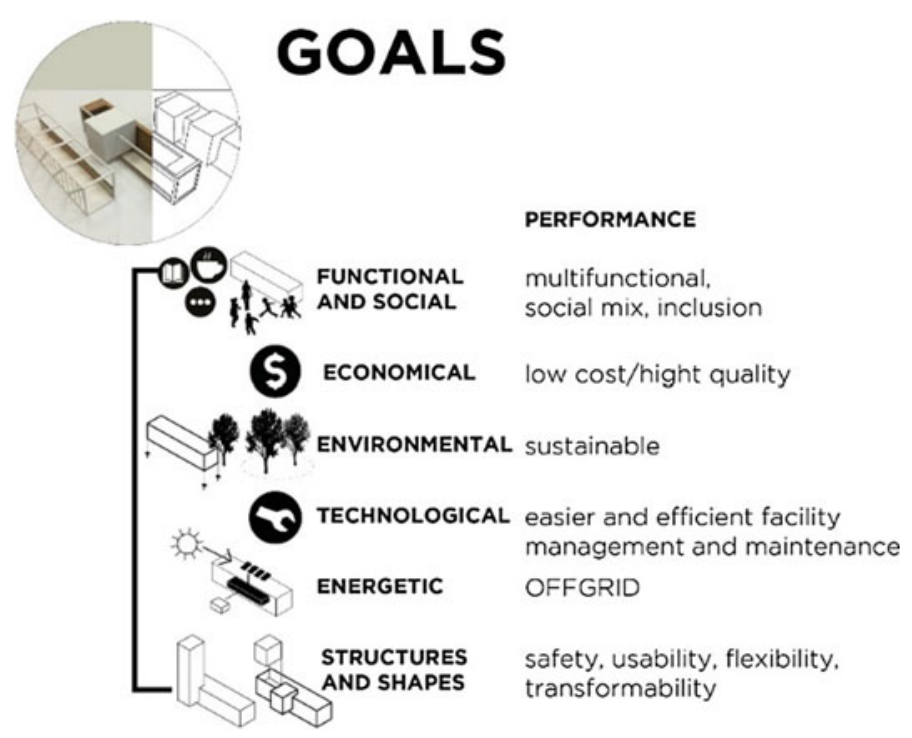

Fig. 6 'multiplyCITY: container TOOLS' goals of the project proposal

and Wi-Fi points for small electronic devices, if energy self-production systems are set up.

To increase the functional possibilities, the dimensions of the basic spatial device may be increased through the 10' BOX shipping containers, TOOL $\beta$, and the 20 ' or 40' HC shipping container, TOOL $\gamma$, here placed vertically. These elements are connected by clamping techniques, in order to facilitate assembly, disassembly, and modification operations and support the reuse of the employed material (Fig. 6).

The TOOLS provide useful services to the community in response to the requirements of flexibility, transformability, recognisability, and energy autonomy. This objective is pursued through the introduction of multifunctional spaces for meetings and exhibitions, as well as for supporting socialization and promoting sport and tourist fruition by hosting further possible functions such as playrooms, info-points with wireless connectivity, and bike-sharing services.

The project has been studied to be self-sufficient from an energetic point of view (i.e., energetic independent) thanks to the adoption of an OFFGRID solution, which makes it completely disconnected from the electricity and gas supply networks. It is powered by renewable sources, directly producing the electricity needed to meet the energy needs (Fig. 7).

Electricity is generated by photovoltaic panels placed on the roof. The produced energy is then accumulated and distributed by the equipped platform, TOOL. Among the various functional configurations, the plant system admits the inclusion of toilets, assuming the presence of water supply network in the area. The addition of data logger and remote management brings out the most performing functions, addressing the 


\section{ENERGY PRODUCTION}

PHOTOVOLTAIC SYSTEM

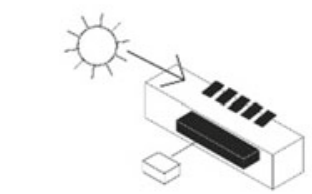

5 PANELS, 6 kWh (on May)

\section{DAILY CONDITIONS OF USE}

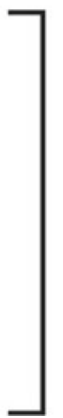

SMARTPHONES CHARGING (50 kWh each) 120 smartphones

LAPTOPS CHARGING (500 kWh each) 12 laptops

TABLETS CHARGING (100 kWh each) 60 tablets

ELECTRIC BIKES CHARGING (700 kWh each) 8 electric bikes

1". STREET FOOD CHARGING (5.6 kWh)

Fig. 7 'multiplyCITY: container TOOLS': possible daily use of the photovoltaic energy system produced

most useful ones. Digital data provide useful information about use frequency and environmental monitoring.

\section{Conclusion: Potential and Future Developments}

The proposal provides for a multidisciplinary approach (technical, social, environmental, economic, etc.) and, within a smart city scenario, refers/pertains to smart manufacturing and industry 4.0 technologies (Internet of Things, digital fabrication, etc.).

The proposed devices can become a landmark system able to acquire knowledge and to transform the environment, being disposed to adapt to the dynamism of their users while posing a minimal intervention (economic sustainability) and remaining reversible (environmental sustainability). Consistently with the incremental development for urban reactivation (institutional sustainability), it pursues multifunctionality and energy independence objectives.

The devices are able to interact and adjust to the social context in which they are placed, improving it (social sustainability); this goal is achieved through the creation of a relationship system able to expand and to 'contaminate' the urban environment that needs to be revitalized (Fig. 8). 


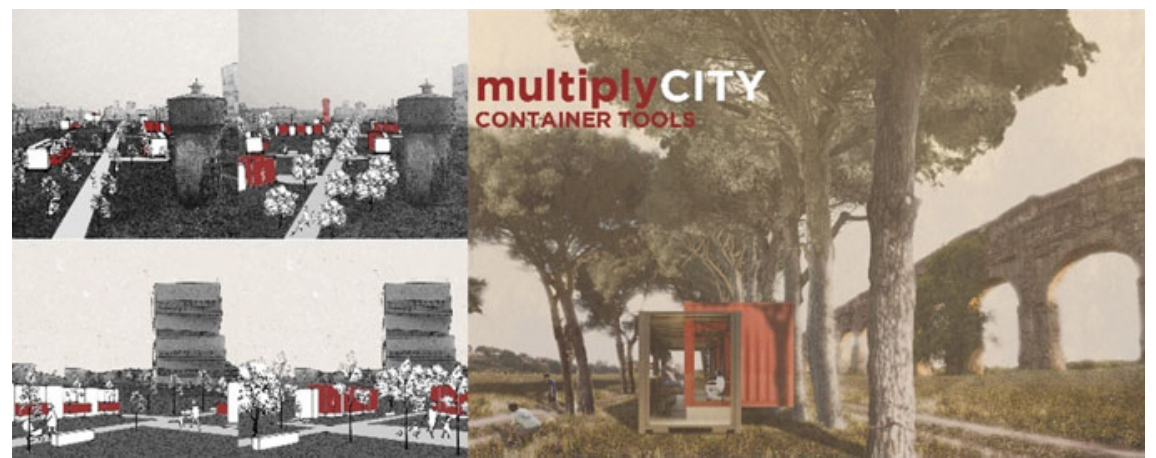

Fig. 8 'multiplyCITY: container TOOLS': TOOL evolution within Porta Romana, Milan and possible insertion in different contexts, i.e., Parco degli acquedotti, Rome

\section{References}

Augé, M. (2009). Nonluoghi. Introduzione a una antropologia della surmodernità. Milano: Eèuthera. II ed (ed. or. 1992 Non-lieux. Paris: Editions du Seuil).

Dardi, C. (1992). Elogio della piazza. In L. Barbiani (a cura di), La piazza storica italiana: analisi di un sistema complesso. Venezia: Marsilio.

Ginelli, E. (a cura). (2015). L'orditura dello spazio pubblico. Per una città di vicinanze. Milano: Mimesis.

Ginelli, E., Lazzati, G., Pirillo, D., Pozzi, G., Vignati, G. (2019). Il progetto cHOMgenius: relazioni virtuose fra progetto, prodotti e impresa. in U\&C. UNIFICAZIONE E CERTIFICAZIONE 5 2019.

INU Istituto Nazionale di Urbanistica. (2013) Carta dello Spazio Pubblico.

Istituto Nazionale di Urbanistica. (2009). Carta dello Spazio Pubblico, Roma: INU.

Kotnik, J. (2008). Container architecture. Barcellona: Links.

Kramer, S. (2015). The box, architectural solution with container. Salenstein: Braun Editore DA AGGIUNGERE IN ARTICOLO CHOMGENIUS.

Losasso, M. (2015). Rigenerazione urbana: prospettive di innovazione. in Techne TECHNE 10 2015.

Lynch, K. (1960). The image of the city. Cambridge: The MIT Press.

Santagata, W. (2009). Libro bianco sulla creatività. Per un modello italiano di sviluppo. Milano: Università Bocconi Editore.

Stiles, R. (a cura di). (2009). Manuale per spazio urbano. Istituto di disegno e architettura del paesaggio. Politecnico di Vienna. 
Open Access This chapter is licensed under the terms of the Creative Commons Attribution 4.0 International License (http://creativecommons.org/licenses/by/4.0/), which permits use, sharing, adaptation, distribution and reproduction in any medium or format, as long as you give appropriate credit to the original author(s) and the source, provide a link to the Creative Commons license and indicate if changes were made.

The images or other third party material in this chapter are included in the chapter's Creative Commons license, unless indicated otherwise in a credit line to the material. If material is not included in the chapter's Creative Commons license and your intended use is not permitted by statutory regulation or exceeds the permitted use, you will need to obtain permission directly from the copyright holder.

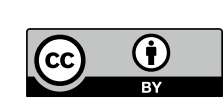

